Power Systems and Complexes

Энергетические системы и комплексы

DOI: $10.17516 / 1999-494 X-0360$

УДК 621.31; 004.942

\title{
Integral Indicator of the Efficiency Assessment \\ and Energy Saving Potential \\ in the Municipal Public Sector
}

\author{
Eugenia Yu. Sizganova*, \\ Lyudmila S. Sinenko and Alexander Yu. Yuzhannikov \\ Siberian Federal University \\ Krasnoyarsk, Russian Federation
}

Received 27.11.2021, received in revised form 30.11.2021, accepted 15.12.2021

\begin{abstract}
The paper presents a method to assess the efficiency and the potential of energy saving in the municipal public sector on the example of the network of Krasnoyarsk municipal educational institutions. It is performed according to criteria expressions based on the law of optimal formation of technocenosis by comparing two integral indicators, one of them characterizes a positive effect, and another one expresses costs.
\end{abstract}

Keywords: energy saving, energy efficiency, costs, useful effect, educational institutions, electrical energy consumption.

Acknowledgements. The study was carried out with the financial support of the Krasnoyarsk Regional Fund for the Support of Scientific and Technical Activities.

Citation: Sizganova, E. Yu., Sinenko, L.S., Yuzhannikov, A. Yu. Integral indicator of the efficiency assessment and energy saving potential in the municipal public sector, J. Sib. Fed. Univ. Eng. \& Technol., 2021, 14(8), 894-902. DOI: 10.17516/1999-494X-0360

(C) Siberian Federal University. All rights reserved

This work is licensed under a Creative Commons Attribution-Non Commercial 4.0 International License (CC BY-NC 4.0).

* Corresponding author E-mail address: seu_eset@mail.ru 


\title{
Интегральный показатель оценки эффективности \\ и потенциала энергосбережения \\ в муниципальной бюджетной сфере
}

\author{
Е.Ю. Сизганова, \\ Л. С. Синенко, А. Ю. Южанников \\ Сибирский федеральный университет \\ Российская Федераџия, Красноярск
}

\begin{abstract}
Аннотация. Статья предлагает способ оценки эффективности и потенциала энергосбережения в муниципальной бюджетной сфере на примере сети муниципальных образовательных учреждений города Красноярска, который выполнен по критериальным выражениям, основанным на законе оптимального построения техноценозов путем сопоставления двух интегральных показателей, один из которых характеризует получаемый положительный эффект, а второй - затраты.
\end{abstract}

Ключевые слова: энергосбережение, энергоэффективность, затраты, полезный эффект, образовательные учреждения, электропотребление.

Благодарности. Исследование выполнено при финансовой поддержке Правительства Красноярского края, Красноярского краевого фонда поддержки научной и научно-технической деятельности.

Цитирование: Сизганова, Е.Ю. Интегральный показатель оценки эффективности и потенциала энергосбережения в муниципальной бюджетной сфере / Е. Ю. Сизганова, Л. С. Синенко, А. Ю. Южанников // Журн. Сиб. федер. ун-та. Техника и технологии, 2021, 14(8). С. 894-902. DOI: 10.17516/1999-494X-0360

Бюджетные организации, предприятия и учреждения являются крупными потребителями топливно-энергетических ресурсов. Они вынуждены осуществлять мероприятия по повышению энергетической эффективности, поскольку энергосбережению в России стали уделять большое внимание. Расходы бюджетов всех уровней на энергозатраты составляют значительную часть всех бюджетных расходов. В связи с этим одной из важнейших задач в области энергосбережения выступает проведение мероприятий, обеспечивающих снижение величины бюджетных средств, направляемых на дотирование энергопотребления организаций.

Проведенный анализ структуры электропотребления бюджетных организаций и учреждений показал, что самым энергоемким объектом является жилищно-коммунальное хозяйство, на которое приходится порядка 75-77 \% потребления электроэнергии. Второй энергоемкий объект - образовательные учреждения, на них приходится около 13 \% потребления электроэнергии.

Рассмотрим способ оценки эффективности и потенциала энергосбережения в муниципальной бюджетной сфере на примере сети муниципальных образовательных учреждений города Красноярска (табл. 1).

Сеть учреждений дошкольного образования города представлена 183 муниципальными дошкольными образовательными учреждениями и 18 структурными подразделениями при средних школах. Кроме этого, на территории города Красноярска функционируют 14 индивидуальных предпринимателей (1133 ребенка) и 13 частных дошкольных учреждений (1550 детей), оказывающих услуги дошкольного образования и присмотра и ухода за детьми.

$$
-895 \text { - }
$$


Таблица 1. Сеть муниципальных бюджетных учреждений

Table 1. Network of municipal budgetary institutions

\begin{tabular}{|c|c|}
\hline Наименование & $\begin{array}{l}\text { Количество, } \\
\text { ед. }\end{array}$ \\
\hline Сеть образовательных учреждений, в том числе & 323 \\
\hline Дошкольные учреждения & 183 \\
\hline Общеобразовательные учреждения & 115 \\
\hline Учреждения дополнительного образования детей & 18 \\
\hline $\begin{array}{l}\text { Образовательные учреждения для детей, нуждающихся в психолого-педагогической } \\
\text { и медико-социальной помощи }\end{array}$ & 7 \\
\hline \multicolumn{2}{|l|}{ кроме того: } \\
\hline Централизованные бухгалтерии & 6 \\
\hline Красноярский информационно-методический центр & 1 \\
\hline $\begin{array}{l}\text { Центр обеспечения безопасного функционирования учреждений отрасли } \\
\text { «Образование» }\end{array}$ & 1 \\
\hline Контингент образовательных учреждений & $\begin{array}{l}\text { Количество, } \\
\text { чел. }\end{array}$ \\
\hline Количество воспитанников в муниципальных ДОУ & 52688 \\
\hline Количество учащихся в муниципальных общеобразовательных учреждениях & 118883 \\
\hline Количество учащихся в учреждениях дополнительного образования детей & 31043 \\
\hline
\end{tabular}

В условиях дефицита бюджетных средств исполнительные власти Российской Федерации предпринимают всевозможные меры для сокращения расходов энергоресурсов бюджетными организациями. Для этого вводятся лимиты на потребление энергетических ресурсов, которые определяются на основе норм удельных показателей электропотребления с учетом обеспечения безаварийного функционирования организаций и возможностей оплаты за потребляемые энергоресурсы.

Применяемые способы определения лимитов имеют низкую точность расчетов параметров электропотребления и не учитывают большинство факторов, определяющих энергозатраты, поэтому они не могут считаться научно обоснованными. Большинство действующих методик по лимитированию, нормированию электропотребления бюджетных организаций следует классическим представлениям электротехники, основанным на расчете режимов работы электрооборудования. Существует и подход, предполагающий использование удельных показателей норм, которые являются среднеотраслевыми оценками уровня потребности в электроэнергии и ее электроэффективности, не распространяются на все бюджетные организации министерства, т. е. не учитываются ценологические свойства $[3,5]$ инфраструктуры бюджетных организаций. Иначе говоря, среднее может быть неприменимо к конкретному объекту, давая ошибку на 50, 100 \% и более. Следовательно, существующую нормативную базу по электропотреблению нельзя корректно использовать для решения конкретных практических задач по энергосбережению. По существу, сейчас все сводится к написанию некоторых чисел, приборами (по счетчику) не проверяемых, а получаемых в результате торга-соглашения между потребителем электроэнергии и тем, кто контролирует ее расход $[5,6]$. 
Понятие энергосбережения бюджетных организаций должно создаваться на рыночной ценологической оценке электроэффективности, основанной на переходе от энергетических обследований отдельной организации к системному энергоаудиту всех учреждений выделенного класса объектов [4]. Это уменьшит число энергетических аудитов, которые являются трудоемкой и затратной составляющей управления энергосбережением бюджетных организаций.

Закономерности электропотребления каждой организации индивидуальны. Его необходимо лимитировать по статистическим данным на уровне раздела организация-энергосистема, применяя некоторые техноценологические положения. В частности, нормирование параметров электропотребления по электроприемникам не должно быть «расчетным» снизу, а затем агрегироваться на более высокие иерархические уровни.

Таким образом, в условиях жесткого государственного лимитирования бюджетных организаций особую актуальность приобретают работы по объективной оценке, эффективности энергопотребления.

Динамика электропотребления сети образовательных учреждений приведена на рие. 1a, где по оси $X$ - объект исследования, по оси $Y$ - значение электрической энергии, израсходованной за $i$-й месяц (МВт.ч), по оси $Z$ - временной интервал (месяц).

Проанализировать и учесть влияние всех прямых и косвенных факторов, оказывающих влияние на уровень электропотребления, практически невозможно из-за отсутствия численных показателей большинства из них. Все это увеличивает сложность модели.

Методом наименьших квадратов [2, 3] получены коэффициенты аппроксимирующих зависимостей (степенной, логарифмической, экспоненциальной функций и полинома четвертой степени). Низкие значения коэффициентов детерминации и сравнительно высокие величины сумм квадратов остатков, рассчитанные для оценки качества сглаживания, не позволяют использовать полученные модели для анализа и прогнозирования параметров электропотребления предприятия с приемлемой точностью.

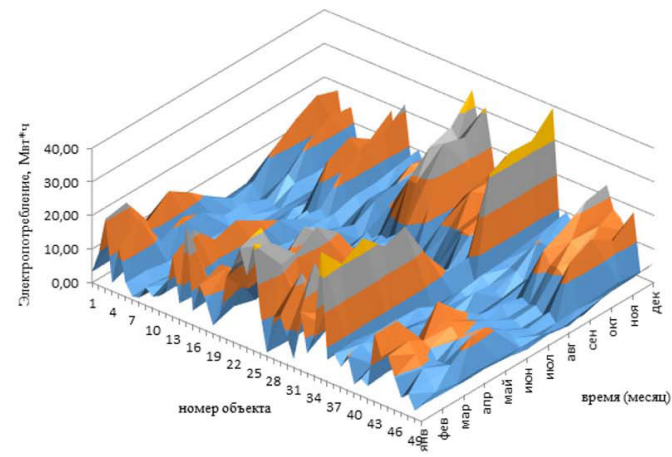

a)

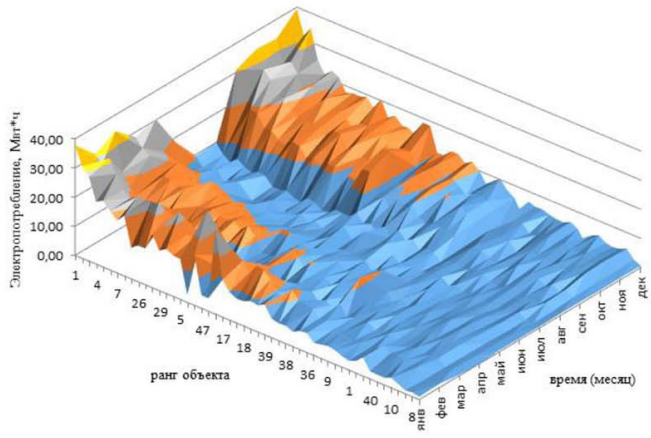

б)

Рис. 1. Электропотребление сети образовательных учреждений г. Красноярска: а - динамика; б - ранговая поверхность

Fig. 1. Electricity consumption of the network of educational institutions in Krasnoyarsk: $a-$ dynamics; $b$ - rank surface 
Если проранжировать потребление электроэнергии в порядке убывания величины (рис. 1б) и применить для анализа полученного рангового распределения тот же математический аппарат, то качество регрессионных моделей существенно повышается.

Оценка эффективности и потенциала энергосбережения сети образовательных учреждений города Красноярска может быть выполнена по критериальным выражениям, основанным на законе оптимального построения техноценозов [1].

Оптимизация процесса электропотребления должна осуществляться одновременно на двух системных уровнях:

1. Внедрение эффективных решений, которые направляются на энергосбережение в рамках конкретных технологических процессов (технические мероприятия).

2. Управление сетью образовательных учреждений города Красноярска организационными методами с целью снижения электропотребления до минимального уровня, обеспечивающего нормальное функционирование образовательных учреждений.

Эффективность процесса энергосбережения сети образовательных учреждений может быть оценена сопоставлением двух интегральных показателей, один из которых характеризует получаемый положительный эффект, а второй - затраты.

Положительный эффект может быть получен от внедрения методологии оптимального управления электропотреблением и оценивается интегральным показателем (1), который формально исчисляется в диапазоне от 0 до 1, т. е. от полного отсутствия энергосберегающих процедур до «абсолютного энергосбережения», которое позволяет свести электропотребление к нулю.

$$
I P_{W}=\frac{\int_{0}^{\infty} W_{1}(r) d r-\int_{0}^{\infty} W_{2}(r) d r}{\int_{0}^{\infty} W_{1}(r) d r}
$$

где $W_{1}(r)$ - ранговое параметрическое распределение образовательных учреждений по электропотреблению, построенное в результате имитационного моделирования, при условии отсутствия управляющего воздействия, направленного на энергосбережение; $W_{2}(r)$ - ранговое параметрическое распределение образовательных учреждений по электропотреблению, полученное при наличии управляющего воздействия.

Затраты на внедрение методологии оптимального управления электропотреблением оцениваются интегральным показателем (2), который формально исчисляется в диапазоне от 1 до бесконечности (от нулевых затрат на выполнение мероприятий по энергосбережению до бесконечных).

$$
I P_{Z}=1+\frac{\int_{0}^{\infty} Z_{2}(r) d r}{\int_{0}^{\infty} Z_{1}(r) d r}
$$

где $Z_{2}(r)$ - ранговое параметрическое распределение образовательных учреждений по затратам на внедрение энергосберегающих технологий, построенное по результатам моделирования; $Z_{1}(r)$ - ранговое параметрическое распределение образовательных учреждений по затратам на оплату за потребленную электроэнергию применительно к варианту без управляющих воздействий.

Критерием эффективности является максимизация интегрального показателя эффективности: 


$$
I P=\frac{I P_{W}}{I P_{Z}} \underset{k \in[1, n]}{\longrightarrow} \max
$$

при выполнении ограничений:

$$
W\left(r_{k}\right)-\frac{\left\{\Phi\left(p_{\delta}\right)\right\}^{-1}\left[\sigma_{k}\right]}{2} \leq w_{k} \leq W\left(r_{k}\right)+\frac{\left\{\Phi\left(p_{\delta}\right)\right\}^{-1}\left[\sigma_{k}\right]}{2}
$$

где $-\{\Phi(x)\}^{-1}=\left\{\frac{1}{2 \pi} \int_{0}^{x / 2} e^{-\frac{y^{2}}{2}} d y\right\}^{-1}$ обратная функция Лапласа, задающая нижнюю и верхнюю границы доверительного интервала; $n$ - общее количество образовательных учреждений; $w_{k}$ - эмпирическое значение электропотребления k-го образовательного учреждения, получаемое по результатам имитационного моделирования; $W\left(r_{k}\right)$ - электропотребление, соответствующее рангу к-го образовательного учреждения на кривой $W(r) ; p_{\delta}-$ априорно принимаемая $95 \%$-я доверительная вероятность; $\left[\sigma_{k}\right]$ - эмпирический стандарт распределения $W(r)$ в кластеpe k-го образовательного учреждения.

Очевидно, что интегральный показатель эффективности (3) находится в пределах от 0 до 1, формально приобретая свое критериальное значение при строгом выполнении равенства: $I P=1$. Реально критериальное значение показателя $I P$ должно определяться с учетом минимальных технологических потребностей образовательных учреждений в электроэнергии, которые соответствуют нижней границе переменного доверительного интервала - левая часть неравенства (4).

В общем случае неравенство (4) определяет необходимость реализации процесса электропотребления во всех образовательных учреждениях города Красноярска в границах гауссового переменного доверительного интервала, определяемого в ходе интервального оценивания. При этом не допускается снижение электропотребления объектов ниже значения, определяющего минимальные технологические потребности, которые задаются нижней границей переменного доверительного интервала (рис. 2). Эти два условия (4) должны конъюнктивно выполняться на всей области определения рангового параметрического распределения $(\mathrm{k} \in[1, n])$.

Визуализация такого важного прогнозного параметра, как потенциал энергосбережения, представлена на рис. 3.

В качестве потенциала энергосбережения образовательных учреждений рассматривается числитель критериального выражения (1), вычисленный по результатам оптимизационного процесса, при выполнении ограничений (3) и (4):

$$
\Delta W_{t}=\int_{0}^{\infty} W_{1}(r) d r-\int_{0}^{\infty} W_{2}(r) d r
$$

где $\Delta W_{t}$ - потенциал энергосбережения образовательных учреждений (кВт×ч) на глубину времени $t$.

Оценка эффективности и потенциала энергосбережения образовательных учреждений города Красноярска осложняется необходимостью осуществления практической внедренче-

$$
-899-
$$




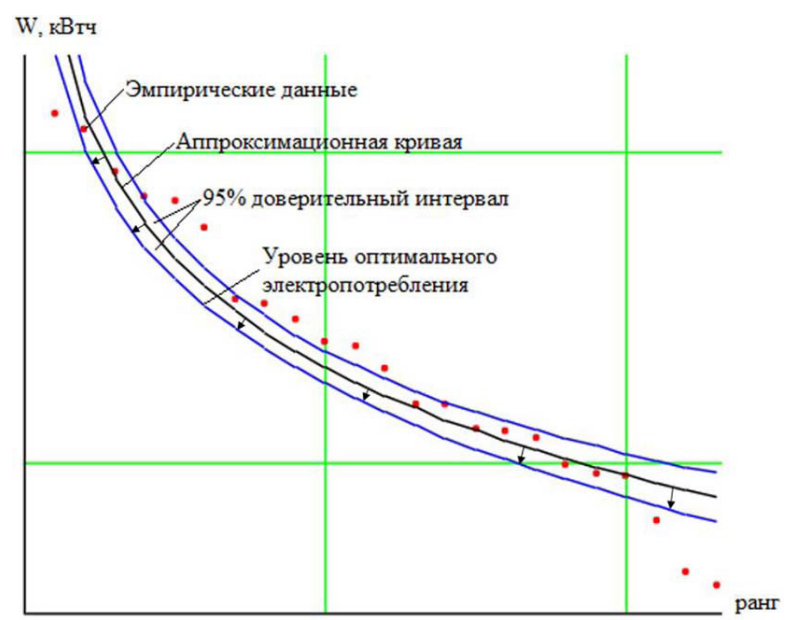

Рис. 2. Направление оптимизации электропотребления образовательных учреждений

Fig. 2. Direction of optimization of electricity consumption in educational institutions

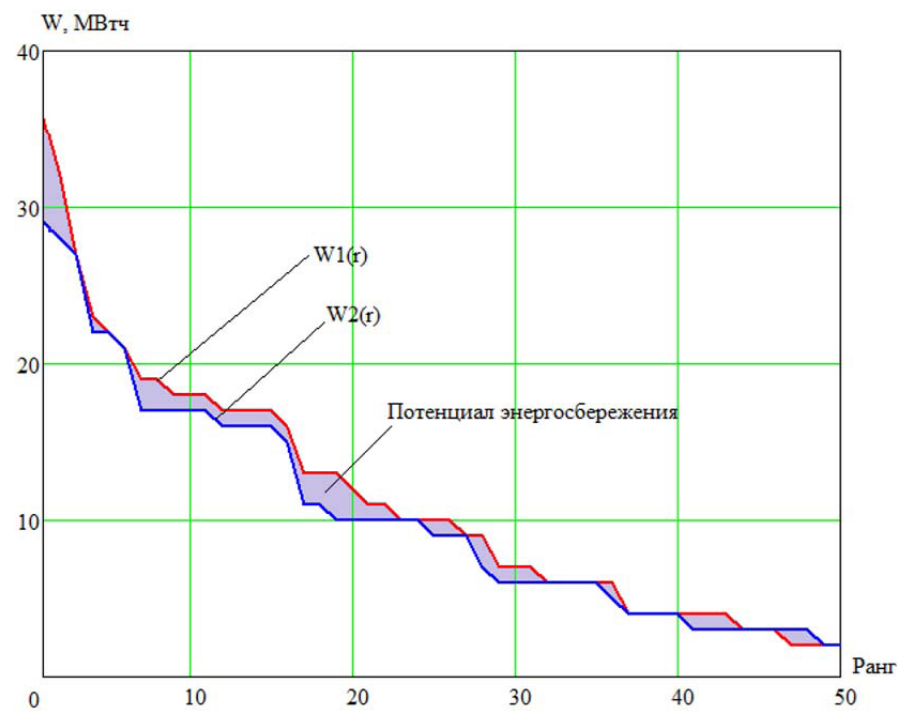

Рис. 3. Потенциал энергосбережения

Fig. 3. Energy Saving Potential

ской работы, растягивающейся на несколько лет, а ответ, как правило, необходимо иметь еще до принятия решения об использовании предлагаемого метода. Поскольку исследование ряда динамических параметров, которые описывают процесс электропотребления, в рамках данного исследования не проводили, были приняты два допущения:

1. При отсутствии в системе управления стимулирующих воздействий, которые направлены на энергосбережение, в качестве математического ожидания и стандарта принимаются соответствующие параметры нормы, вычисленной для кластера. В противном случае математическое ожидание уменьшается в k1 раз, а стандарт - в k2 раза.

$$
-900-
$$


2. Все результаты электропотребления, превышающие норму, заменяются ее максимальным значением для данного объекта. Если же электропотребление объекта при моделировании окажется меньше нижней границы нормы, то в качестве электропотребления объекта принимается минимальное значение нормы.

На рис. 3 представлено сравнение электропотребления образовательных учреждений к исходу цикла моделирования для двух вариантов: W1 - электропотребление объектов при отсутствии мероприятий по энергосбережению; W2 - электропотребление объектов в условиях проведения мероприятий по энергосбережению.

Таким образом, под потенциалом энергосбережения понимается полученная в результате моделирования на расчетную глубину времени абсолютная разница (в кВт×ч) между электропотреблением образовательных учреждений без реализации энергосберегающих мероприятий и процедур, с одной стороны, и электропотреблением, полученным в результате внедрения методологии оптимального управления электропотреблением на системном уровне с реализацией комплекса технических и технологических мероприятий - с другой.

\section{Список литературы / References}

[1] Гнатюк В.И. Закон оптимального построения техноценозов. М: Изд-во ТГУ, Центр систем исследований, 2005. 384 c. [Gnatyuk V.I. The law of optimal construction of technocenoses. Moscow, Publishing house of Tomsk State University, Center for Research Systems, 2005.384 p. (in Russian)]

[2] Соснина Е.Н., Шалухо А.В. Моделирование энергопотребления образовательных учреждений, Информачионно-измерительные и управляющие системы, 2011, 7, 66-70. [Sosnina E.N., Shalukho A.V. Modeling of energy consumption of educational institutions, Information-measuring and control systems, 2011, 7, 66-70 (in Russian)]

[3] Сизганова Е.Ю., Южанников А. Ю., Филиппов В.П. Нормы электропотребления в бюджетной сфере, Приоритетные направления науки, техники, технологии; материалы II Международной научной интернет-конференции. Черногория (Бечичи): Фундаментальные исследования, 2007. 8. 41-42. [Sizganova E. Yu., Yuzhannikov A. Yu., Filippov V. P. Electricity consumption norms in the budgetary sphere, Priority directions of science, technology, technology; materials of the II International Scientific Internet Conference. Montenegro (Becici): Fundamental Research, 2007.8.41-42. (in Russian)]

[4] Антоненков Д. В., Сизганова Е.Ю., Петухов Р.А. Способ определения объектов с нерациональным электропотреблением в инфраструктуре бюджетных организаций и учреждений муниципального уровня, Журнал СФУ. Техника и технологии. 2013. 6(5). 605-613. [Antonenkov D. V., Sizganova E. Yu., Petukhov R. A. A method for identifying objects with irrational power consumption in the infrastructure of budgetary organizations and municipal institutions, J. Sib. Fed. Univ. Eng. technol., 2013, 6(5), 506514 (in Russian)]

[5] Антоненков Д.В., Сизганова Е.Ю., Южанников А.Ю. Энергосбережение образовательных учреждений: на примере Нерюнгринского района Республики Саха (Якутия), Красноярск: СФУ, 2015, 156 с. [Antonenkov D. V., Sizganova E. Yu., Yuzhannikov A. Yu. Energy saving of educational institutions: on the example of the Neryungri region of the Republic of Sakha (Yakutia), Krasnoyarsk: SFU, 2015, 156 p (in Russian)]

$$
-901-
$$


[6] Сизганова Е.Ю., Южанников А.Ю., Филиппов В.П. Энергосбережение в образовательной сфере г. Красноярска, Энергосбережение и водоподготовка. 2007, 3(47), 30-33. [Sizganova E. Yu., Yuzhannikov A. Yu., Filippov V.P. Energy saving in the educational sphere of Krasnoyarsk, Energy saving and water treatment, 2007, 3 (47), 30-33 (in Russian)] 